\title{
Stopgap spending bill leaves US scientists in limbo
}

\section{Proposal would keep funding flat for most research agencies, but cuts could come early next year.}

Ramin Skibba

07 December 2016 I Updated: 07 December 2016

In what has become a year-end tradition in Washington DC, the US Congress is getting ready to approve a stopgap spending measure before it adjourns for the holidays.

The legislation introduced yesterday in the House of Representatives would hold spending flat at most science agencies, with some limited increases. These include an extra US\$872 million to implement provisions of the 21 st Century Cures Act, a bill that would reform drug development and biomedical research. The money would be split between the National Institutes of Health, the Food and Drug Administration and state governments.

The House passed the Cures Act on 29 November, the Senate approved the bill on 7 December and President Barack Obama is expected to sign it.

The stopgap funding bill, which would expire on 28 April, also allows for extra funding to keep a handful of major multiyear space programmes on track. These include the National Oceanic and Atmospheric Administration's Joint Polar Satellite System, a series of probes designed to monitor Earth's weather and climate, as well as NASA efforts to explore deep space and develop a replacement for the retired space shuttle.

But for most science programmes, funding would remain at roughly the same level as in the past fiscal year. And continuing to operate under a temporary funding measure means that agencies cannot start new programmes or end old ones without explicit permission from Congress.

"Every time you delay a [final] spending bill, it prevents the science agencies from doing the planning they need, and it keeps them in limbo," says Lexi Shultz, director of public affairs for the American Geophysical Union in Washington DC.

Operating the government under a series of short-term bills can create uncertainty for scientists who depend on federal research grants. Each time a spending bill is passed, it takes weeks for agencies to divvy up their funds between various programmes.

"I feel bad for people waiting for a new grant. How do you sustain a career when you don't know what you're doing in six months?" says Jennifer Zeitzer, director of legislative relations at the Federation of American Societies for Experimental Biology in Bethesda, Maryland.

\section{New president, new worries}

The current fiscal year runs until 30 September 2017, about five months after the stopgap bill would expire. The House is expected to vote on the stopgap measure on 8 December; to become law, it would also need to be approved by the Senate and signed by Obama.

But many researchers are more worried about what might come after this temporary funding extension, if it is approved. When president-elect Donald Trump takes office on 20 January 2017, Republicans will control the White House and both houses of Congress — and their science priorities are very different from those of outgoing President Barack Obama, a Democrat.

Trump and other prominent Republicans — such as Representative Lamar Smith, the Texan who leads the House Committee on Science, Space, and Technology — have criticized research in the Earth sciences, especially studies of climate change. Scientists who work in these fields worry that politicians will move in 2017 to slash government funding for such research.

And in recent years, Republican legislators including Smith and Representative John Culberson of Texas have sought to curb funding for the social sciences at the National Science Foundation. Smith has also introduced legislation that would require the agency to certify that each grant it awards serves "the national interest". Democrats, and some science groups, have suggested that this is a tactic to reduce support for research on topics such as social science and climate change. 
"The election didn't result in a loss of our major critics, unfortunately," says Wendy Naus, executive director of the Consortium of Social Science Associations in Washington DC.

Nature | doi:10.1038/nature.2016.21112

\section{Updates}

Updated:This post has been updated to reflect the fact that the Senate approved the 21st Century Cures Act on 7 December. 